\title{
Maternal uniparental disomy of chromosome 1
}

INSERM

\section{Source}

INSERM. (1999). Orphanet: an online rare disease and orphan drug data base. Maternal uniparental disomy of chromosome 1. ORPHA:251009

Maternal uniparental disomy of chromosome 1 is an uniparental disomy of maternal origin that most likely does not have any phenotypic expression except from cases of homozygosity for a recessive disease mutation for which only mother is a carrier. 